\title{
Corrosion Inhibition Activity of an Expired Antibacterial Drug in Acidic Media amid Elucidate DFT and MD Simulations
}

\author{
Shefali Dahiya ${ }^{a}$, Nisha Saini ${ }^{a}$, Naveen Dahiya ${ }^{b}$, Hassane Lgaz $^{c, d}$, \\ Rachid Salghi ${ }^{d}$, Shehdeh Jodeh ${ }^{e}$ and Suman Lata ${ }^{a,}$ \\ ${ }^{a}$ Deenbandhu Chhotu Ram University of Science and Technology, \\ Murthal, Sonepat, Haryana, India \\ ${ }^{b}$ Maharaja SurajMal Institutes of Technology, C4 Janak Puri, New Delhi, India \\ ${ }^{c}$ Laboratory of separation processes, Faculty of Science, University Ibn Tofail, \\ P.O. Box 242, Kenitra, Morocco \\ ${ }^{d}$ Laboratory of Applied Chemistry and Environment, ENSA, Ibn Zohr University, \\ P.O. Box 1136, 80000 Agadir, Morocco \\ ${ }^{e}$ Department of Chemistry, An-Najah National University, P.O. Box 7, Nablus, Palestine
}

Received March 30, 2017; accepted September 20, 2017

\begin{abstract}
An expired drug with non-toxic characteristics has been evaluated as a corrosion inhibitor for mild steel alloy. The corrosion inhibition efficiency of the expired ethambutol drug in a $0.5 \mathrm{M} \mathrm{HCl}$ solution has been studied using weight loss, electrochemical impedance spectroscopy (EIS), electrochemical polarization, scanning electron microscopy (SEM) and molecular dynamics (MD) techniques. The results showed that the drug provides appreciable inhibition efficiency, more than $95 \%$ at the higher concentration, i.e., $1000 \mathrm{ppm}$. The Tafel polarization plots have shown that the expired drug acted as a mixed type inhibitor. Langmuir adsorption isotherm, along with physiochemical mode of interaction, has proved that the corrosion inhibition process accords with the isotherm. The outcomes obtained from all the experimental techniques and theoretically obtained information are in good correlation. MD simulations reveal that the studied compound adsorbs onto the surface of mild steel in the planar orientation.
\end{abstract}

Keywords: drug; adsorption; corrosion; molecular dynamics.

\section{Introduction}

Due to the enormous applicability and continuous exposure to different kind of environments, mild steel (MS) comes across problems like scaling, oxidized film formation and rusting. Rusting is the corrosion of iron and its alloys, which deteriorates the metals, silently affecting the major part of economy worldwide. The use of corrosion inhibitors as a protective measure is the best suited option

\footnotetext{
*Corresponding author. E-mail address: sumanjakhar.chem@dcrustm.org
} 
for preventing mild steel from rusting. The most effective, eco-friendly and efficient corrosion inhibitors are the organic compounds which are either synthesized or naturally occurring. Among them, drugs (chemical medicines) seem to be ideal corrosion inhibitors to replace conventional and harmful compounds, because they sufficiently fall in the category of non-toxic, biodegradable, and environment friendly inhibitors [1-5].

As low-cost and effective compounds, expired drugs are attractive to the present corrosion chemists, and can be a better substitute for expensive drugs and other organic compounds [6-7]. More than $90 \%$ of the drugs have retained their stability, even a long time after the expiry dates, with infinitesimal degradation of their active constituents [4]. Two expired drugs, carbamazepine and paracetamol, have also been tested by Nicolae, as corrosion inhibitors for carbon steel in acidic media, and have obtained 95 and $85 \%$ efficiency, respectively [6]. Furthermore, the use of expired drugs (due to their bio-degradability) also minimizes environmental pollution, as well as their disposal cost [4-7]. Structurally, the choice of some of the drugs used as corrosion inhibitors is based upon the following facts [8-11]:

- the molecules with $\pi$ bonds, hetero atoms (P, S, N, and $\mathrm{O}$ ) and aromatic rings even substitute benzene rings, and are very frequent. In turn, heterocycles, such as pyridines, furans, thiophenes, imidazoles, isoxazoles and others, are active centers;

- they are reportedly very important in biological reactions (i.e., not hazardous and environmentally friendly);

- and they can be easily produced and purified.

The present paper clings to the application of drugs as corrosion inhibitors. The drug herein used is an expired chemical, and of no further clinical usage; it is medical waste, but the components present still are chemical substances, retain their activity and, hence, protect the materials against corrosion [4, 6, 11]. To further prove the activity of this expired drug as an inhibitor, all the practical and theoretical techniques, i.e., weight loss method, electrochemical impedance spectroscopy (EIS), electrochemical polarization, scanning electron microscopy (SEM) and molecular dynamics (MD), were employed in this study.

\section{Materials and methods}

The used material was mild steel with the composition w/w $\% 0.14 \mathrm{C}, 0.03 \mathrm{Si}$, $0.032 \mathrm{Mn}, 0.05 \mathrm{~S}, 0.20 \mathrm{P}, 0.01 \mathrm{Ni}, 0.01 \mathrm{Cu}, 0.01 \mathrm{Cr}$ and balanced Fe. The specimens of $3 \mathrm{~cm} \times 1.5 \mathrm{~cm} \times 0.028 \mathrm{~cm}$ size were cut from the sheet, whereas for electrochemical investigations, the exposed surface area of the specimen was 1.0 $\mathrm{cm}^{2}$. All the specimens were mechanically polished with the help of emery papers of grades 400, 600, 800, 1000 and 1200, thoroughly washed with double distilled water and acetone, and thereafter, dried and preserved in desiccators, until the experimental work was carried out.

The used $\mathrm{HCl}$ was of AR grade from Sigma Aldrich, and the solutions were prepared using double distilled water to make a $0.5 \mathrm{M} \mathrm{HCl}$ solution as the 
aggressive medium for the experimental setup. The used inhibitor is an expired drug, which was added in varying concentrations from $200 \mathrm{ppm}$ to $1000 \mathrm{ppm}$. The commercially available drug is named Ethambutol (E), with IUPAC nomenclature as (2S,2'S)-2,2'-(Ethane-1,2-diyldiimino)dibutan-1-ol. The molecular formula of the drug is $\mathrm{C}_{10} \mathrm{H}_{24} \mathrm{~N}_{2} \mathrm{O}_{2}$, with a molecular weight of 204.31 g/mol. Fig. 1 shows the molecular structure of the expired drug. The white crystalline solid drug partially soluble in cold water is primarily used for the treatment of tuberculosis. It is on the World Health Organization's list of the most important medication needed in a basic health system $[8,9]$. The drug is herein experimented as a corrosion inhibitor, due to the presence of heteroatoms in its molecular structure, and for being a medical waste.

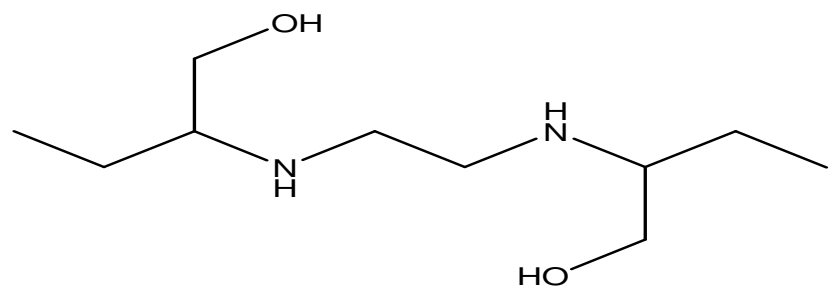

Figure 1. Molecular structure of ethambutol (drug E).

\section{Weight loss (gravimetric) technique}

After recording the initial weights of mild steel coupons, they were immersed in a tilted position in $250 \mathrm{~mL}$ conical flasks with the test solution $(0.5 \mathrm{M} \mathrm{HCl})$ as a corroding medium, in the absence and presence of the inhibitor, for 4 hours. Experiments were carried out in an electronically controlled thermostat at $303 \mathrm{~K}$, $313 \mathrm{~K}, 323 \mathrm{~K}$ and $333 \mathrm{~K}$, with an accuracy of $\pm 2 \mathrm{~K}$. After exposing the specimens for 4 hours at the above mentioned temperatures, the coupons were taken out from the flasks, and initially washed under running tap water. Following that, the coupons were rubbed with rubber cork to loosely remove adhered corrosion products, thoroughly washed with double distilled water, dried, and weighed thereafter [1,3]. After scouring off, these coupons showed a drop in their corresponding initial weights, which depicts the mass loss due to corrosion. From these obtained weight loss data, corrosion rates and percentage inhibition efficiencies at different conditions were computed. All the weight loss investigation was carried out in triplicate, with standard deviation of the order of 0.01 for only a sample.

\section{Electrochemical polarization technique}

In the present study, electrochemical polarization technique was carried out in a $500 \mathrm{~mL}$ glass cell having a three electrode system assembly. Potentiostatic polarization of the working electrode was carried out by using an Autolab Potentiostat / Galvanostat PGSTAT 204T (Netherlands). The working electrode was mild steel (MS), with a $1.0 \mathrm{~cm}^{2}$ area exposed to the corrosive medium during all the experimental set up, and carbon (graphite) electrode was used as counter 
(auxiliary) electrode [1,9]. All the potentials were measured against a pencil type saturated $\mathrm{Ag} / \mathrm{AgCl}$ electrode as reference electrode. A Luggin capillary filled with the test solution was used to connect the reference electrode with the cell. The tip of the Luggin capillary was kept very close to the working area of the electrode, but without touching it, in order to minimize the ohmic drop. The specimen was introduced in the acidic solution, until a constant open circuit potential (OCP) was attained.

After maintaining the constant $\mathrm{OCP}$, linear polarization resistance measurements were potentiostatically carried out by scanning, through a potential range of -0.25 $\mathrm{V}$ to $+0.25 \mathrm{~V}$, with respect to the OCP value at the scan rate of $1 \mathrm{mV}$. Experiments were carried out in the inhibitor absence and presence at $200 \mathrm{ppm}$, $400 \mathrm{ppm}, 800 \mathrm{ppm}$ and $1000 \mathrm{ppm}$ concentrations, and at $303 \mathrm{~K}, 313 \mathrm{~K}, 323 \mathrm{~K}$ and $333 \mathrm{~K}$ temperatures.

\section{Electrochemical impedance spectroscopy (EIS)}

In the present study, electrochemical polarization technique was carried out in a $500 \mathrm{~mL}$ glass cell having a three electrodes system assembly. A typical electrochemical impedance experimental setup consists of an electrochemical cell (the stem under investigation), a potentiostat/galvanostat, and a frequency response analyzer (FRA). The FRA applies the sine wave and analyses the response of the system to determine its impedance. Impedance spectroscopy was performed to the same setup of the polarization technique. The parameters were observed on the analyzer in a frequency range of $1.0 \times 10^{5}-1.0 \mathrm{~Hz}$, with the peak-to-peak AC signal of $5 \mathrm{mV}$ at open circuit potential, stabilized at $303 \mathrm{~K} \pm 1$ $\mathrm{K}$ for $4 \mathrm{hrs}$. The main parameter inferred from the Nyquist diagram analysis is the charge transfer resistance, $R_{c t}$ (diameter of high frequency loop), then calculated to give the double layer capacitance, $\mathrm{C}_{\mathrm{dl}}$. The Nyquist plots for MS in acidic media are not perfect semicircles, due to the non-homogeneity of the surface and roughness of the metal $[1,9]$.

\section{Scanning electron microscopy (SEM)}

The mild steel coupons, thoroughly polished and dried, were exposed to their respective acidic media, for four hours, at $303 \mathrm{~K}$. Polishing was performed using SiC papers from 400, 800, 1000 and 2000, washed with double distilled water and dried in acetone. These coupons were immersed in $0.5 \mathrm{M} \mathrm{HCl}$ in the absence and presence of $1000 \mathrm{ppm}$ of the drug used as inhibitor [1]. After immersion, these coupons were scorned off to remove the corrosion product formed over the surface, washed and dried for imaging under Model Zeiss Ultra 55 at $3 \mathrm{kV}$ for FESEM technique at X500 magnification.

\section{Molecular modeling detail}

Geometry optimization, quantum chemical parameters and Fukui functions indices calculations were performed using a reliable $\mathrm{DMol}^{3}$ method implemented in the high-performance software (Materials Studio version 6.0) [12, 13]. The GGA was the gradient-corrected functional method used with a double numeric plus polarization (DNP) basis set, and a functional Becke One Parameter (BOP). 
The solvation effects (aqueous phase) were included in $\mathrm{DMol}^{3}$ calculations by COSMO [14] controls. Molecular dynamic (MD) simulations of the tested inhibitor were carried out in a simulation box with periodic boundary conditions, using Materials Studio 6.0 (from Accelrys Inc.). The iron crystal was imported and cleaved along a ( $\left.\begin{array}{lll}1 & 1 & 0\end{array}\right)$ plane, and a slab of $5 \AA$ was employed. The Fe $\left(\begin{array}{lll}1 & 1\end{array}\right.$ 0 ) surface was relaxed, by minimizing its energy using a smart minimizer method, and enlarged to a $(10 \times 10)$ supercell, to provide a large surface for the inhibitor interaction. A vacuum slab with zero thickness was built. A supercell with a size of $\mathrm{a}=\mathrm{b}=24.82 \AA$ and $\mathrm{c}=25.14 \AA$ contained $500 \mathrm{H}_{2} \mathrm{O}$ molecules, and a molecule of the tested inhibitor was created. The simulation was carried out in a simulation box $\left(24.82 \times 24.82 \times 35.69 \AA^{3}\right)$ using a discover module with a time step of $1 \mathrm{fs}$, and simulation time of $500 \mathrm{ps}$, performed at $298 \mathrm{~K}$, with NVT ensemble, and COMPASS force field [15]. In the simulation system, the interactions between the inhibitor and Fe $\left(\begin{array}{lll}1 & 1 & 0\end{array}\right)$ can be understood by adsorption and binding energies, calculated using Equation (1) and (2) [16]:

$$
\begin{gathered}
E_{\text {adsorption }}=E_{\text {total }}-\left(E_{\text {surface+solution }}+E_{\text {inhibitor+solution }}\right)+E_{\text {solution }} \\
E_{\text {adsorption }}=-E_{\text {binding }}
\end{gathered}
$$

where $E_{\text {total }}$ is the total energy of the entire system, $E_{\text {surface }}+$ solution refer to the total energy of the Fe (lllll 110$)$ surface and the solution without the inhibitor, Einhibitor + solution represent the total energy of the inhibitor and the solution, and $\mathrm{E}_{\text {solution }}$ is the total energy of the $\mathrm{H}_{2} \mathrm{O}$ molecules.

\section{Results and discussion}

The studied drug is expired ethambutol, used for corrosion inhibition purposes, up to a concentration of $1000 \mathrm{ppm}$, using different techniques. The value of 1000 ppm is the highest concentration of the drug providing maximized inhibition capability, as depicted in the present study. The same drug has also been applied as a new inhibitor by Kumar and Bashir [11], according to whom it reaches its optimization level at $1000 \mathrm{ppm}$ and, afterwards, its performance goes down. The employed techniques are below discussed under the sub-heads.

\section{Gravimetric technique}

The weight loss of a rectangular specimen of size $3 \mathrm{~cm} \mathrm{x} 1.5 \mathrm{~cm} \times 0.028 \mathrm{~cm}$ in $0.5 \mathrm{M} \mathrm{HCl}$, in the absence and presence of inhibitors, was determined after a $4 \mathrm{~h}$ period of immersion at different temperatures. The corrosion rate (CR) shown in Table 1 in mmpy was calculated from the following equation:

$$
C R=\frac{87.6 \times W}{D A t}
$$

where $\mathrm{W}$ is the average weight loss of mild steel specimens (mg), A is the total area of one MS specimen in $\mathrm{cm}^{2}, \mathrm{t}$ is the immersion time (4h) and D is the density of mild steel $\left(7.86 \mathrm{gcm}^{-3}\right)[1,9]$. 
Table 1. Weight loss details at varying temperatures and concentrations of the inhibitor.

\begin{tabular}{|c|c|c|c|c|c|c|c|c|}
\hline \multirow{2}{*}{$\begin{array}{c}\text { Conc. of } \\
\text { inhibitor in } \\
0.5 \mathrm{M} \mathrm{HCl} \\
\text { (ppm) }\end{array}$} & \multicolumn{2}{|c|}{$303 \mathrm{~K}$} & \multicolumn{2}{|c|}{$313 \mathrm{~K}$} & \multicolumn{2}{|c|}{$323 \mathrm{~K}$} & \multicolumn{2}{|c|}{$333 \mathrm{~K}$} \\
\hline & $\begin{array}{c}\text { CR } \\
(\mathrm{mmpy})\end{array}$ & $\%$ IE & $\begin{array}{c}\text { CR } \\
(\mathrm{mmpy})\end{array}$ & $\%$ IE & $\begin{array}{c}\text { CR } \\
(\mathrm{mmpy})\end{array}$ & $\%$ IE & $\begin{array}{c}\text { CR } \\
(\mathrm{mmpy})\end{array}$ & $\%$ IE \\
\hline 0 & 8.36 & - & 10.22 & - & 12.69 & - & 16.09 & - \\
\hline 200 & 0.86 & 89.69 & 0.96 & 90.62 & 1.30 & 89.74 & 1.86 & 88.42 \\
\hline 400 & 0.43 & 94.85 & 0.57 & 94.37 & 1.00 & 92.11 & 1.51 & 90.64 \\
\hline 800 & 0.29 & 96.41 & 0.45 & 95.63 & 0.86 & 93.23 & 1.35 & 91.61 \\
\hline 1000 & 0.03 & 99.60 & 0.19 & 98.06 & 0.16 & 98.75 & 0.55 & 96.58 \\
\hline
\end{tabular}

The inhibition efficiency of the drug is found to increase with its increasing concentration in the acidic medium, and decreases with the increasing range of temperature. Fig. 2 shows the plot of corrosion rate (mmpy) against the inhibitor concentration (ppm) for the corrosion of mild steel in $0.5 \mathrm{M} \mathrm{HCl}$, with increasing temperatures in the range of $303 \mathrm{~K}$ to $333 \mathrm{~K}$.

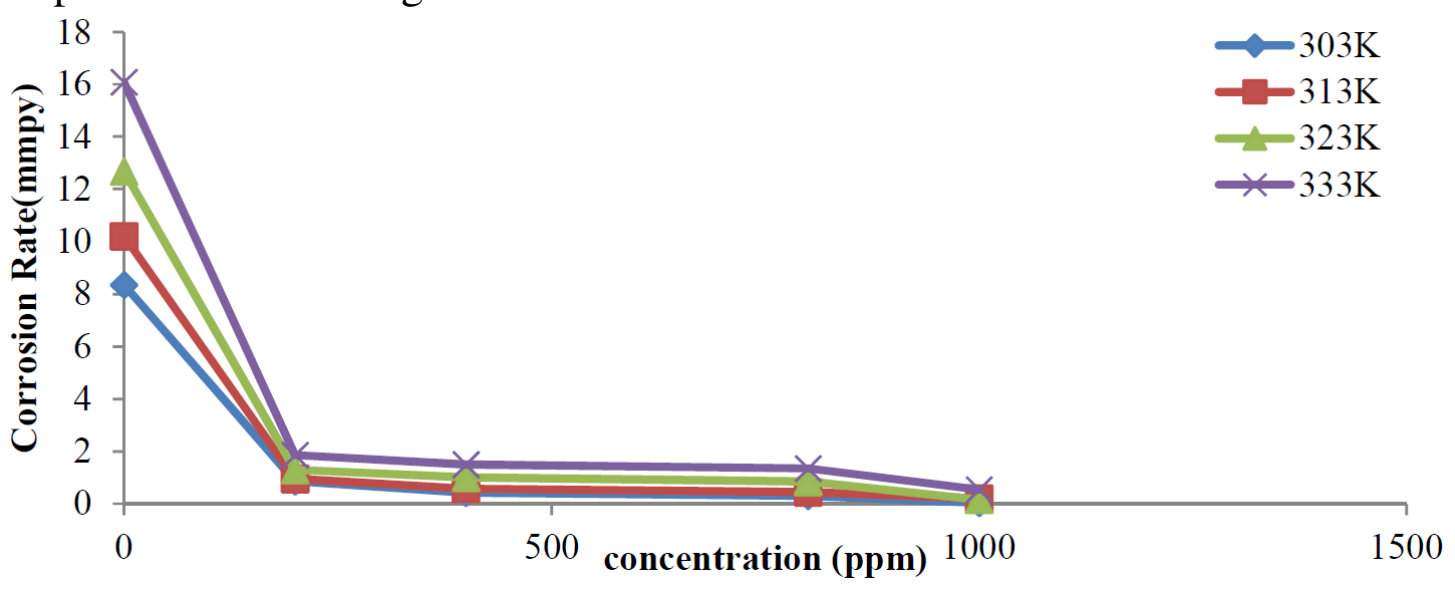

Figure 2. Gravimetric plot showing concentration vs. corrosion rate in the range $303 \mathrm{~K}$ $-333 \mathrm{~K}$.

The corrosion rate, for instance, was found to be $8.35 \mathrm{mmpy}$ for an uninhibited MS coupon, and $0.03 \mathrm{mmpy}$ for the inhibited coupon at $303 \mathrm{~K}$ temperature, and $1000 \mathrm{ppm}$ of the drug had standard deviation of the order of 0.01 for a sample, but not for the population. The inhibition efficiency (IE \%) of the inhibitor on the corrosion of MS was calculated [17] as follows (equation 4):

$$
I E \%=\frac{W-W_{\text {inh }}}{W_{\text {inh }}} X 100
$$

where $\mathrm{W}$ and $\mathrm{W}_{\text {inh }}$ are the weight loss of mild steel in the absence and presence of the inhibitor, respectively.

Fig. 2 showed that the corrosion rate, calculated from equation 1, goes down as the concentration of the inhibitor increases, and it increases with increasing temperatures. The weight loss experiments were performed in triplicate, and an average reading was considered for further estimates. The technique is roughly considered as an average inhibition technique [17], because the corrosion process intended through this phenomenon has a four hours interval, and the variation corresponding to the time coverage is not considered. 

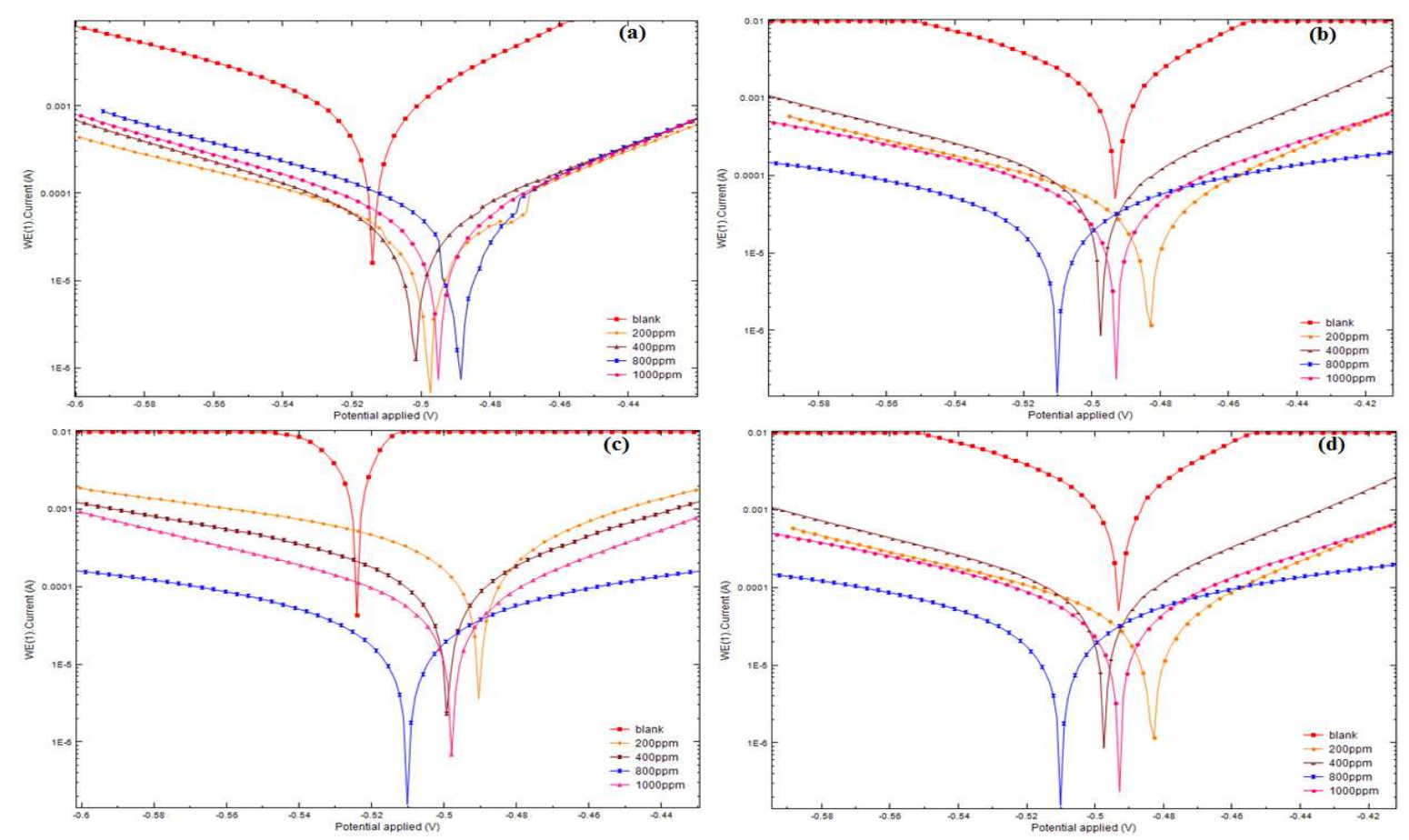

Figure 3. Tafel slopes of inhibitor per saturated $\mathrm{Ag} / \mathrm{AgCl}$ electrode at (a) $303 \mathrm{~K}$, (b) $313 \mathrm{~K}$, (c) $323 \mathrm{~K}$ and (d) $333 \mathrm{~K}$.

\section{Electrochemical polarization measurements}

Inspection of the data reveals that the inhibition efficiency increases with increasing inhibitor concentrations (Table 2). This behavior can be attributed to the increased adsorption and coverage of inhibitors onto the mild steel surface with increasing inhibitor concentrations. Since the $\mathrm{E}_{\text {corr }}$ values with the inhibiting drug do not show any significant deviation from those of $E_{\text {corr }}$ blank values (Fig. 3 ) and the polarization curves of both halves, the anodic and cathodic half reactions are not equally affected by the drug addition. The polarization curves with small deviations depict the inhibitor as from the mixed type [1, 17].

$$
\% \mathrm{I} . \mathrm{E}=\left(\mathrm{I}_{\text {corr- }} \mathrm{I}_{\text {corr }}^{\mathrm{o}}\right) \mathrm{I}_{\text {corr }} \mathrm{x} 100
$$

\section{Electrochemical impedance spectroscopy}

The Nyquist plots contain a depressed semi-circle, with the center below the real $\mathrm{X}$-axis, when increasing the inhibitor concentration, which indicated that corrosion was mainly a charge transfer process $[18,19]$. The depressed semicircle is a characteristic of solid electrodes, and often refers to the dispersion frequency which arises due to the roughness and homogeneities of the surface [17-19]. The impedance parameters derived from these plots are given in Table 3 , which were computed using equation 6 .

$$
\% \mathrm{IE}=\left(\mathrm{R}_{\mathrm{ct}}^{\mathrm{o}}-\mathrm{R}_{\mathrm{ct}}\right) / \mathrm{R}_{\mathrm{ct}}^{\mathrm{o}} \times 100
$$


Table 2 . Polarization parameters and corresponding inhibition efficiencies.

\begin{tabular}{|c|c|c|c|c|c|c|c|}
\hline Temp. & $\begin{array}{l}\text { Concentration } \\
\text { of inhibitor } \\
(\mathbf{p p m})\end{array}$ & $\begin{array}{c}\text {-Ecorr per saturated } \\
\text { Ag/AgCl electrode } \\
(\mathrm{mV})\end{array}$ & $\begin{array}{c}\boldsymbol{\beta}_{\mathrm{a}} \\
(\mathrm{mV} / \mathrm{dec})\end{array}$ & $\begin{array}{c}-\boldsymbol{\beta}_{\mathrm{c}} \\
(\mathrm{mV} / \mathrm{dec})\end{array}$ & $\begin{array}{c}\mathbf{i}_{\text {corr }} \\
\left(\mathrm{mA} / \mathrm{cm}^{2}\right)\end{array}$ & I.E. (\%) & $\Theta$ \\
\hline \multirow{6}{*}{$303 \mathrm{~K}$} & 0 & 504 & 111.3 & 68.56 & 1.326 & 0 & 0 \\
\hline & 200 & 499 & 196.82 & 87.21 & 0.117 & 91.17 & 0.912 \\
\hline & 400 & 507 & 136.88 & 124.12 & 0.093 & 93.01 & 0.930 \\
\hline & 800 & 492 & 141.02 & 88.04 & 0.032 & 97.61 & 0.976 \\
\hline & 1000 & & & & & & \\
\hline & & 498 & 121.98 & 73.93 & 0.008 & 99.35 & 0.993 \\
\hline \multirow[t]{3}{*}{$313 \mathrm{~K}$} & $\begin{array}{r}0 \\
200\end{array}$ & $\begin{array}{l}493 \\
497 \\
501 \\
512\end{array}$ & $\begin{array}{l}102.86 \\
116.68 \\
104.16 \\
114.88\end{array}$ & $\begin{array}{l}58.61 \\
72.78 \\
73.66 \\
84.61\end{array}$ & $\begin{array}{l}2.537 \\
0.204 \\
0.117 \\
0.092\end{array}$ & $\begin{array}{c}0 \\
91.96 \\
95.37 \\
96.35\end{array}$ & $\begin{array}{l}0 \\
0.919 \\
0.954 \\
0.963\end{array}$ \\
\hline & $\begin{array}{l}400 \\
800\end{array}$ & & & & & & \\
\hline & 1000 & 498 & 91.51 & 73.02 & 0.062 & 97.54 & 0.975 \\
\hline \multirow[t]{3}{*}{$323 \mathrm{~K}$} & $\begin{array}{r}0 \\
200\end{array}$ & $\begin{array}{l}512 \\
482 \\
501 \\
507\end{array}$ & $\begin{array}{c}108.86 \\
154.31 \\
85.5 \\
121.84\end{array}$ & $\begin{array}{l}88.02 \\
99.52 \\
81.39 \\
95.71\end{array}$ & $\begin{array}{l}3.571 \\
0.512 \\
0.238 \\
0.087\end{array}$ & $\begin{array}{c}0 \\
85.66 \\
93.32 \\
97.54\end{array}$ & $\begin{array}{l}0 \\
0.856 \\
0.933 \\
0.975\end{array}$ \\
\hline & $\begin{array}{l}400 \\
800\end{array}$ & & & & & & \\
\hline & 1000 & 497 & 117.59 & 88.77 & 0.074 & 97.91 & 0.979 \\
\hline \multirow[t]{4}{*}{$333 \mathrm{~K}$} & $\begin{array}{r}0 \\
200\end{array}$ & $\begin{array}{l}530 \\
502 \\
500 \\
512\end{array}$ & $\begin{array}{l}144.17 \\
167.51 \\
120.74 \\
135.69\end{array}$ & $\begin{array}{r}36.93 \\
93.96 \\
95.56 \\
103.52\end{array}$ & $\begin{array}{l}5.501 \\
0.542 \\
0.269 \\
0.097\end{array}$ & $\begin{array}{c}0 \\
90.14 \\
95.11 \\
98.23\end{array}$ & $\begin{array}{l}0 \\
0.901 \\
0.951 \\
0.982\end{array}$ \\
\hline & 400 & & & & & & \\
\hline & 800 & & & & & & \\
\hline & 1000 & 529 & 142.35 & 114.87 & 0.094 & 98.29 & 0.983 \\
\hline
\end{tabular}

The $R_{c t}$ values of the inhibited substrate are increased as the concentration of the inhibitor increases. On the other hand, the values of $\mathrm{C}_{\mathrm{dl}}$ are decreased as the concentration of the inhibitor gets enhanced, which probably happened due to the decrease in local dielectric constant and/or to the increase in thickness of the electrical double layer. The Nyquist plots are given in the absence and presence of the inhibitor, individually from Fig. 4(a) and Fig. 5, whereas Fig. 4(b) gives an equivalent circuit diagram of the EIS study, respectively, with $R_{s}, R_{p}$ or $R_{c t}$ 
and $\mathrm{C}_{\mathrm{dl}}$ values. It is clear that the impedance response of MS was significantly changed after the drug addition.

Table 3. EIS data of the inhibitor.

\begin{tabular}{|c|c|c|c|}
\hline $\begin{array}{c}\text { Concentration of inhibitor } \\
(\mathbf{p p m})\end{array}$ & $\begin{array}{c}\mathbf{R}_{\mathrm{ct}} \\
\left(\Omega \cdot \mathrm{cm}^{2}\right)\end{array}$ & $\begin{array}{c}C_{d l} \\
\left(\mu \mathrm{Fcm}^{-2}\right)\end{array}$ & $\begin{array}{l}\text { I.E } \\
(\%)\end{array}$ \\
\hline Blank & 14.174 & 214.0 & - \\
\hline 200 & 104.28 & 36.7 & 86.40 \\
\hline 400 & 124.74 & 31.4 & 88.63 \\
\hline 800 & 173.63 & 28.7 & 91.83 \\
\hline 1000 & 225.84 & 25.2 & 93.72 \\
\hline
\end{tabular}

(a)

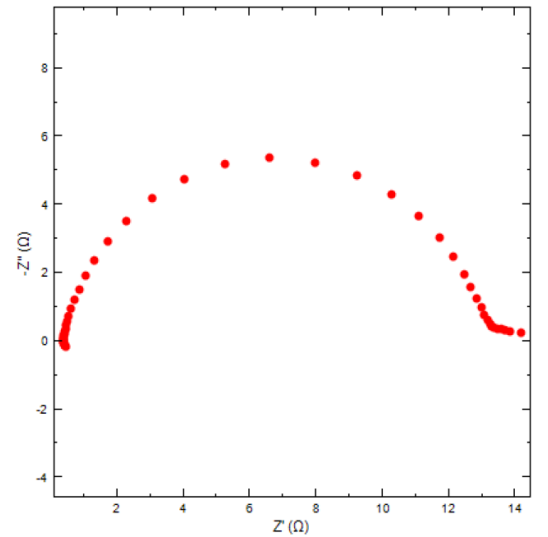

(b)

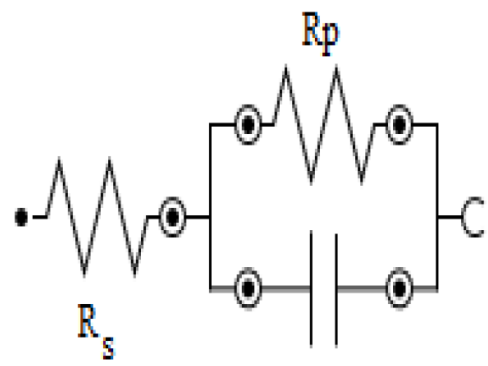

C

Figure 4. (a) Nyquist plot in the absence of inhibitor; (b) equivalent circuit diagram of EIS study.

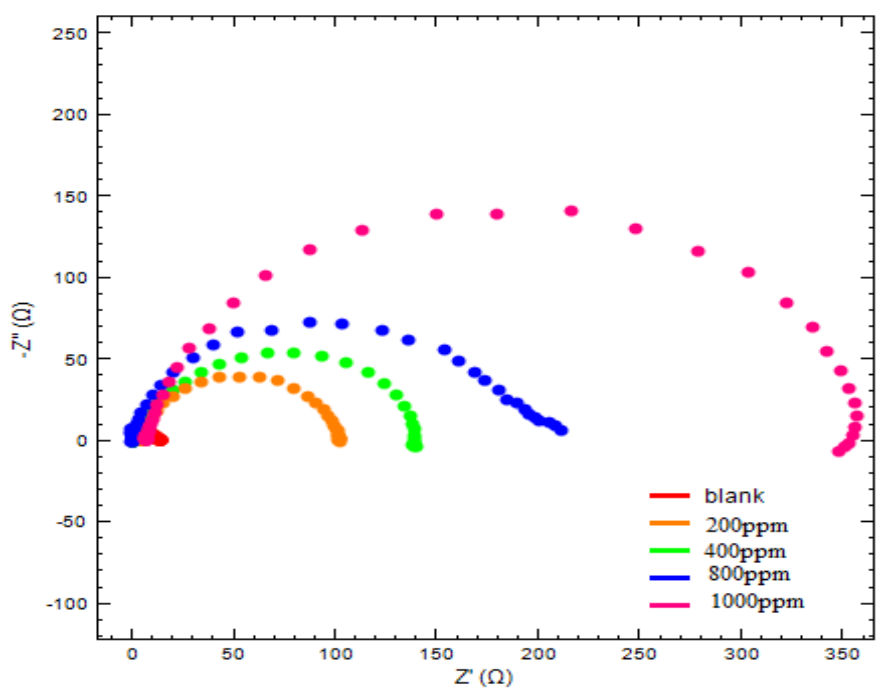

Figure 5. Nyquist plots for $\mathrm{MS}$ in $0.5 \mathrm{M} \mathrm{HCl}$ at different concentrations of the $\mathrm{E}$ drug at $303 \mathrm{~K}$.

\section{Scanning electron microscopy}

The scanning electron micrographs (Fig. 6), of the uninhibited sample, give evidence of the damage caused to the surface by the acid, and of the inhibited sample, with the formation of a protective layer by the inhibitor at $\mathrm{x} 500$ magnification. The surface morphology of the inhibited metal surface is smoother than that of the uninhibited surface, representing a protective layer of 
the adsorbed inhibitor that prevents corrosion caused by the acid attack on the mild steel surface. The smoothness of the MS surface in the inhibitor presence is due to the barrier of the protective film over the metal surface.

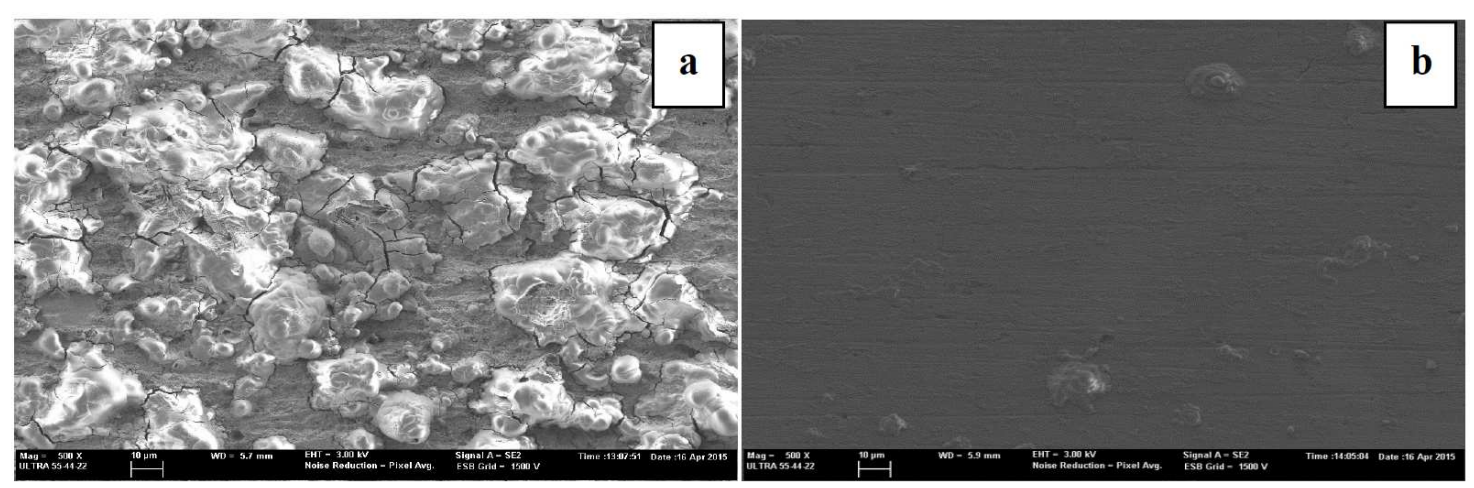

Figure 6. SEM images of the steel surface after $4 \mathrm{~h}$ immersion at $303 \mathrm{~K}$, in the absence (a) and presence (b) of $1000 \mathrm{ppm}$ concentration of the drug, respectively.

\section{DFT calculations}

Global reactivity descriptors

The interaction of corrosion inhibitors and metal surfaces depends on the molecular properties of the inhibitor. These molecular properties are associated with the presence of particular groups on organic molecules, including the presence of heteroatoms, $\pi$-bond, aromatic systems and electron density. It is reported that the molecules with these functional groups highly tend to act as corrosion inhibitors [20, 21]. Highest occupied molecular orbital (HOMO) and lowest unoccupied molecular orbital (LUMO) (Fig.7) play an important role in the reactivity of inhibitors with the metal surface. HOMO is referred to as the orbital that could act as an electron donor, because it is the outermost (highest energy) orbital with electrons, while LUMO is the orbital that could act as the electron acceptor, because it is the innermost (lowest energy) orbital having the capability to accept electrons [22, 23].
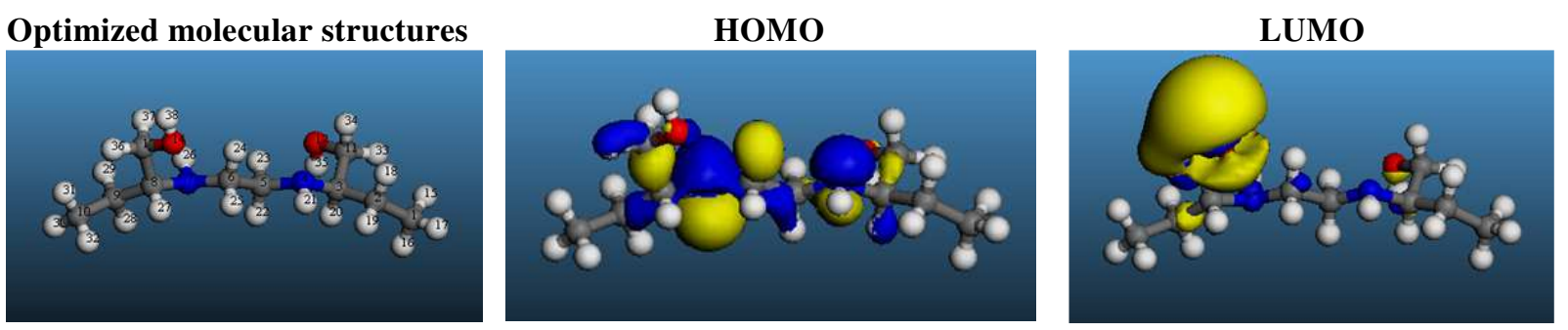

Figure 7. Optimized molecular structure and HOMO and LUMO frontiers orbitals distribution of the inhibitor.

The optimized structure of the studied compound and the corresponding atom numbering are shown in Fig. 7. It is interesting to mention here the type of functional groups present on the inhibitor molecule, since the adsorption onto the metal surface depends on them. Ethambutol has two nitrogen atoms and two 
hydroxyl group atoms; some of their most interesting features to consider are the location of the highest occupied molecular orbital (HOMO) and the lowest unoccupied molecular orbital (LUMO). In the current study, the HOMO orbital is largely distributed in all heteroatoms, while the LUMO orbital is distributed, especially in the hydroxyl group, due to its capability to protonate, and consequently accept electrons from the metal surface through electrostatic interactions.

The quantum chemical calculations parameters such as $\mathrm{E}_{\text {HOMо, }} \mathrm{E}_{\mathrm{Lumo}}, \Delta \mathrm{E}$ and $\Delta \mathrm{N}$ are represented in Table 4 . The electron affinity (EA) and ionization potential (IP) are deduced from Eномо and ELumo by the Equations (7) and (8) [23]:

$$
\begin{aligned}
\mathrm{IP} & =-E_{\text {Hомо }} \\
\mathrm{EA} & =-E_{\text {Lumo }}
\end{aligned}
$$

Mulliken electronegativity $(\chi)$ and absolute hardness $(\eta)$ can be approximated using [24, 25]:

$$
\begin{gathered}
\chi=\frac{I P+E A}{2} \\
\eta=\frac{I P-E A}{2}
\end{gathered}
$$

The number of transferred electrons $(\Delta N)$ is calculated by application of the Pearson method using the following equation [26]:

$$
\Delta N=\frac{\phi-\chi i n h}{2\left(\eta_{F e}+\eta_{\text {inh }}\right)}
$$

where $\emptyset$ is the work function of the iron surface with the value of $4.82 \mathrm{eV}$ for Fe (1 110$)$ [27, 28], $\chi_{\text {inh }}$ is the absolute electronegativity associated to the inhibitor molecule, $\eta_{\mathrm{Fe}}=0$, and $\eta_{\mathrm{inh}}$ is the absolute hardness of metal and the inhibitor molecule, respectively $[29,30]$. Eномо gives information about the tendency of the molecule to donate electrons to an electron poor species [21]. The molecule with the highest $\mathrm{E}_{\mathrm{HOMO}}$ is considered to have the highest tendency to donate electrons to an electron poor species. ELumo, on the other hand, shows the tendency of a molecule to accept electrons, and the lower is the EHOMO value, the greater is the tendency of that particular system to accept electrons [31]. Eномо and $\mathrm{E}_{\mathrm{LUMO}}$ for the study compound are reported in Table 4 . The energy difference between HOMO and LUMO (denoted as $\triangle \mathrm{E}$ ) provides important information on the reactivity of inhibitor molecules. The smaller is $\Delta \mathrm{E}$ value, the greater is the reactivity of a molecule [32]. High reactivity means that the molecule has a greater chance to interact with the metal surface. It was also reported that the $\Delta \mathrm{N}$ value measures the ability of a chemical compound to transfer its electrons to the metal, if $\Delta N>0$, and vice versa, if $\Delta N<0[33,34]$. In this study, the positive value of $\Delta \mathrm{N}$ represented in Table 4 suggests the high capability of the tested inhibitor to donate electrons to the mild steel surface.

Table 4. Computed quantum chemical parameters for tested compounds.

\begin{tabular}{ccccc}
\hline Inhibitor & $\begin{array}{c}\boldsymbol{E}_{\text {HOMO }} \\
(\mathbf{e V})\end{array}$ & $\begin{array}{c}\boldsymbol{E}_{\text {LUMO }} \\
(\mathbf{e V})\end{array}$ & $\begin{array}{c}\Delta \mathbf{E}_{\text {gap }} \\
(\mathbf{e V})\end{array}$ & $\Delta \boldsymbol{N}_{110}$ \\
\hline Ethambutol & -4.066 & 1.527 & 5.59 & 0.634 \\
\hline
\end{tabular}




\section{Local reactivity: Fukui indices}

The Fukui functions provide information about the centers in a molecule, in which nucleophilic and electrophilic reactions are mostly likely to occur [35]. The local reactivity indices also define the most reactive regions in a molecule. The Fukui indices are calculated using the following Equations [36, 37]:

$$
\begin{aligned}
& f_{k}^{+}=q_{k}(N+1)-q_{k}(N) \\
& f_{k}^{-}=q_{k}(N)-q_{k}(N-1)
\end{aligned}
$$

In the above equations, $\mathrm{q}_{\mathrm{k}}(\mathrm{N}), \mathrm{q}_{\mathrm{k}}(\mathrm{N}+1)$ and $\mathrm{q}_{\mathrm{k}}(\mathrm{N}-1)$ are the atomic charges of the systems with $\mathrm{N}, \mathrm{N}+1$ and $\mathrm{N}-1$ electrons, respectively [38]. Table 5 reports the estimated condensed Fukui indices for the non-hydrogen atoms of the studied compound.

Table 5. Fukui indices of ethambutol calculated using $\mathrm{DMol}^{3}$ method.

\begin{tabular}{ccc}
\hline Atoms & $\boldsymbol{f}_{\boldsymbol{k}}^{+}$ & $\boldsymbol{f}_{\boldsymbol{k}}^{-}$ \\
\hline $\mathrm{C}(1)$ & 0.006 & 0.010 \\
$\mathrm{C}(2)$ & 0.006 & 0.005 \\
$\mathrm{C}(3)$ & 0.010 & 0.014 \\
$\mathrm{~N}(4)$ & 0.004 & 0.115 \\
$\mathrm{C}(5)$ & 0.006 & 0.021 \\
$\mathrm{C}(6)$ & 0.006 & 0.028 \\
$\mathrm{~N}(7)$ & 0.009 & 0.183 \\
$\mathrm{C}(8)$ & 0.007 & 0.018 \\
$\mathrm{C}(9)$ & 0.007 & 0.009 \\
$\mathrm{C}(10)$ & 0.006 & 0.014 \\
$\mathrm{C}(11)$ & 0.021 & 0.011 \\
$\mathrm{O}(12)$ & 0.057 & 0.017 \\
$\mathrm{C}(13)$ & 0.042 & 0.023 \\
$\mathrm{O}(14)$ & 0.092 & 0.012 \\
\hline
\end{tabular}

The preferred site for a nucleophilic attack (shown by the highest value of $\mathrm{f}_{\mathrm{k}}^{+}$) is on $\mathrm{O}$ (12), $\mathrm{C}$ (13) and $\mathrm{O}(14)$. The results obtained from these regions are in agreement with the analysis from LUMO, because the same predictions from the site are mostly electron deficient. The highest values of $f_{k}^{-}$are on $\mathrm{N}$ (4) and $\mathrm{N}$ (7). There is a correlation between atoms with an electrophilic attack and those obtained in HOMO (i.e., N (4) and N (7)). The results obtained for these regions in nucleophilic and electrophilic attacks support the high capability of the tested compound to react with the metal surface through donor-acceptor interactions among most reactive sites of our inhibitor (Fig. 8) and the mild steel surface. Additionally, the tested inhibitor has a greater capacity to share the electrons with the metal surface than to accept them. These results appear as a good explanation of the physio-chemisorption mode discussed in the adsorption isotherm section. 


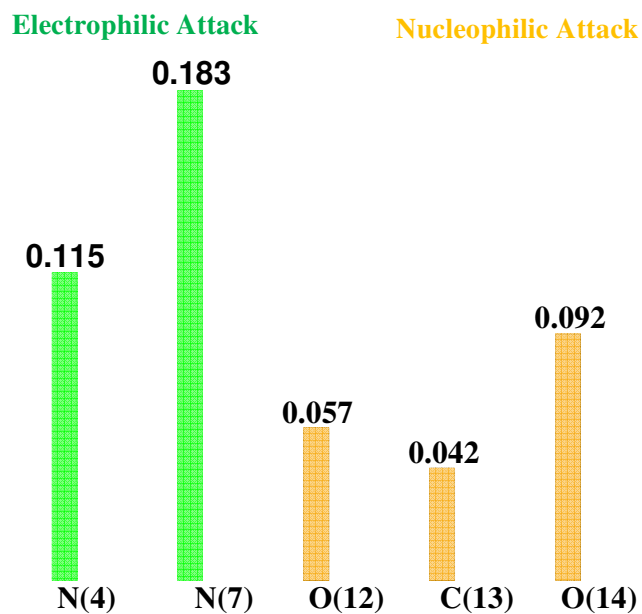

Figure 8. The most reactive centers in the tested inhibitor.

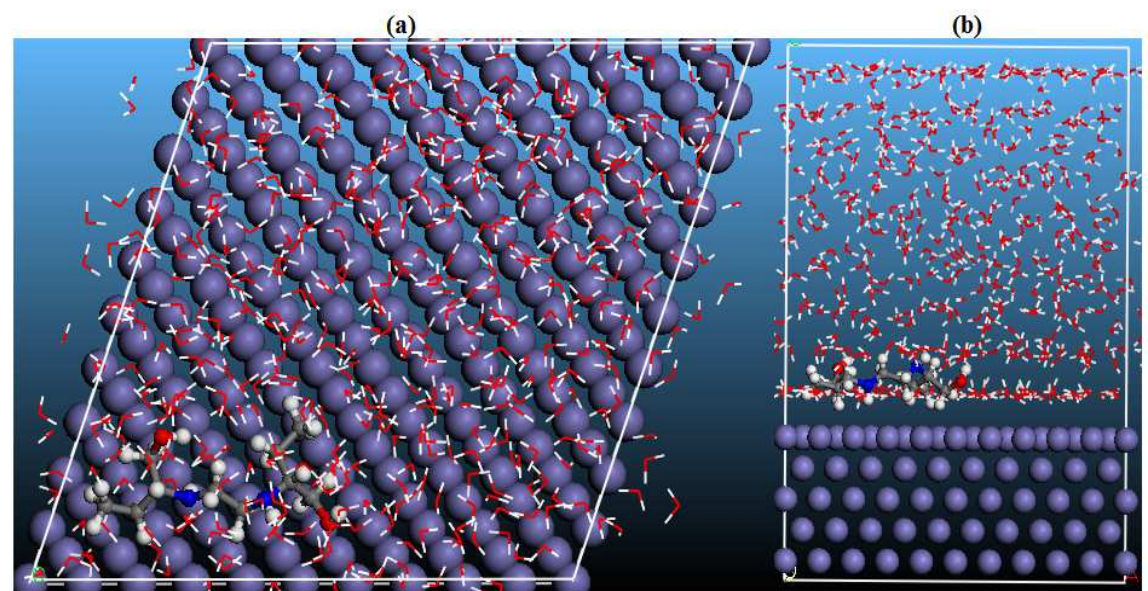

Figure 9. (a) Top and (b) side views of the final adsorption of the tested inhibitor on the $\mathrm{Fe}\left(\begin{array}{lll}1 & 1 & 0\end{array}\right)$ surface in a solution.

\section{Molecular dynamic (MD) simulations}

In recent years, modeling methods based on computer simulations have become a useful tool in solving many scientific and engineering problems [39, 40]. Moreover, with the introduction of powerful workstations, the impact of computer simulations applications is expected to enormously increase in the next few years. In this case, molecular dynamic simulations have been gaining great importance in recent years [41]. This reliable method plays a vital role in explaning the corrosion inhibition process, and in further giving insight into the inhibition action of chemical species used as inhibitors. In this paper, MD simulations of the tested inhibitor were carried out. The system reaches equilibrium only if both energy and temperature achieve a balance [21]. It is evident from Fig. 9 that ethambutol nearly adsorbs in a parallel way to the Fe (1 $10)$ surface.

Table 6 shows both interaction energy and binding energy of the tested inhibitor. What is interesting in this data is that the negative value of interaction energy indicates attractive interactions, while the high magnitude of binding energy 
suggests a better and stable adsorption system [42]. These results are in good agreement with experimental studies, which have shown that the tested drug acts as good corrosion inhibitor of mild steel.

Table 6. Selected energy parameters obtained from MD simulations for adsorption of the inhibitor on the Fe $\left(\begin{array}{lll}1 & 1 & 0\end{array}\right)$ surface.

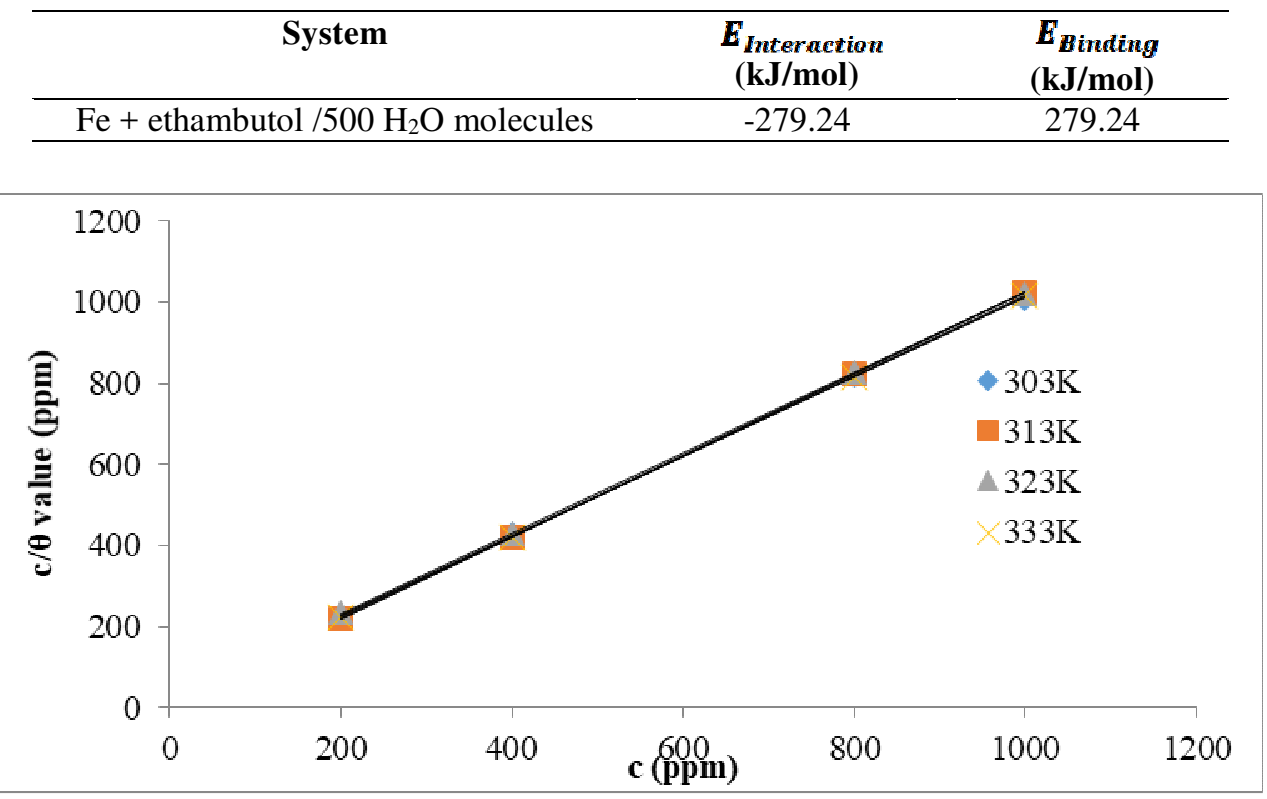

Figure 10. Langmuir adsorption isotherm of the expired drug.

\section{Adsorption isotherm}

The organic inhibitors act through an adsorption phenomenon and hence, decrease the corrosion rate. The inhibitor gets adsorbed onto the metal surface, in the region known as interphase between the MS surface and the medium. The basic information about the interaction between the surface and the studied drug can be determined by adsorption isotherms. The plot of $\mathrm{C} / \theta$ versus $\mathrm{C}$ (Fig. 10) [1, 17] yields a straight line with the correlation coefficient $\left(R^{2}\right)>0.99$, indicating that the adsorption of each drug obeys the Langmuir adsorption isotherm presented in the following equation:

$$
\frac{C}{\theta}=\frac{1}{K_{a d s}}+C
$$

where $\mathrm{C}$ is the inhibitor concentration, $\theta$ is the degree of surface coverage, and $\mathrm{K}_{\mathrm{ads}}$ is the equilibrium constant for the adsorption-desorption process.

The value of the equilibrium constant, $\mathrm{K}_{\mathrm{ads}}$, was calculated from the reciprocal of the intercept of the isotherm plot. $K_{a d s}$ values can be calculated from the intercepts of the straight lines, which are related to the standard free energy of adsorption, $\Delta \mathrm{G}^{0}$ ads, with the following equations $[25,26]$ :

$$
\begin{aligned}
& \Delta G^{0}{ }_{a d s}=-R T \ln 55.5 K_{a d s} \\
& \Delta G^{0}{ }_{a d s}=-2.303 R T\left(\log 55.5 K_{a d s}\right)
\end{aligned}
$$


where $\mathrm{K}_{\mathrm{ads}}$ is the rate constant graphically obtained, $\mathrm{R}$ is a universal gas constant and $\mathrm{T}$ is temperature in Kelvin. $\Delta \mathrm{G}^{0}$ ads was calculated and tabulated in Table 7. The negative values indicate the spontaneity of the adsorption process of the adsorbed layer on the MS surface [17, 18].

Table 7. Free energy of adsorption values $\left(\Delta \mathrm{G}^{0}\right.$ ads $)$.

\begin{tabular}{cccc}
\hline Inhibitor & Temperatures $(\mathbf{K})$ & $\mathbf{R}^{\mathbf{2}}$ & $\left.-\boldsymbol{\Delta} \boldsymbol{G}^{\mathbf{0}}{ }_{\boldsymbol{a d s}} \mathbf{( k J} / \mathbf{m o l}\right)$ \\
\hline $\mathrm{E}$ & 303 & 0.9996 & 29.84 \\
& 313 & 1.0000 & 29.58 \\
& 323 & 1.0000 & 28.31 \\
& 333 & 1.0000 & 30.40 \\
\hline
\end{tabular}

\section{Conclusion}

The studied compound, i.e., ethambutol, is a good inhibitor against corrosion of mild steel in an acidic medium $(0.5 \mathrm{M} \mathrm{HCl})$, with considerable inhibition efficiency. Further, the inhibition efficiency values of the inhibitor go uphill with an increase in its concentration, and downhill at elevated temperatures. The Tafel polarization plots have shown that the expired drug acted as a mixed type inhibitor. The results of the gravimetric analysis, electrochemical polarization and EIS were in very good agreement. The adsorption study showed that the inhibition mechanism obeys Langmuir adsorption isotherm along with the physiochemical mode of interaction, which is also strengthened by the free energy values. A good correlation has been found between quantum chemical calculations and the results experimentally obtained. Furthermore, MD simulations reveal that the studied compound adsorbs onto the surface of mild steel in the planar orientation.

The use of expired drugs can solve two major environmental and economic problems: limitation of environmental pollution with pharmaceutically active compounds, and reduction of the disposal costs of expired drugs. It is reported that the active constituents of drugs degrades only infinitesimally. More than 90 $\%$ of the drugs have maintained stability long time after their expiry dates [15]. Nicolae has tested two expired drugs, carbamazepine and paracetamol, as corrosion inhibitors on carbon steel corrosion in $\mathrm{H}_{2} \mathrm{SO}_{4}$ and $\mathrm{CH}_{3} \mathrm{COOH}$, and has obtained $95 \%$ and $85 \%$ efficiency, respectively [16]. Some of the azosulfamide and antimalarial drugs have been reported as good corrosion inhibitors [17-19].

\section{Acknowledgements}

The authors are grateful to the Dept. of Chemistry, Deenbandhu Chottu Ram University of Science and Technology, Murthal, Sonepat, Haryana, for providing the necessary facilities and encouragement. 


\section{References}

1. Dahiya S, Lata S, Kumar R, et al. Comparative performance of Uroniums for controlling corrosion of steel with methodical mechanism of inhibition in acidic medium: Part1. J Mol Liq. 2016;221:124-132.

2. Sethi T, Chaturvedi A, Upadhyay R, et al. Corrosion inhibitory effects of some Schiff's bases on mild steel in acid media. J Chil Chem Soc. 2007;52:1206-1213.

3. Dehri I, Özcan M. The effect of temperature on the corrosion of mild steel in acidic media in the presence of some sulphur-containing organic compounds. Mater Chem Phys. 2006;98:316-323.

4. Gebhart F. Drug Topics. http://drugtopics.modernmedicine.com/drugtopics/article/articleDetail.jsp?id $=184115$. Accessed 17 Feb 2012.

5. Struck S, Schmidt U, Gruening B, et al. Toxicity versus potency: Elucidation of toxicity properties discriminating between toxins, drugs, and natural compounds. Genome Inform. 2008;20:231-242.

6. Vaszilcsin N, Ordodi V, Borza A. Corrosion inhibitors from expired drugs. Int J Pharm. 2012;431:241-244.

7. Samide A, Tutunaru B, Negrila C. Corrosion inhibition of carbon steel in hydrochloric acid solution using a sulfa drug. Chem Biochem Eng Q. 2011;25:299-308.

8. Gece G. Drugs: A review of promising novel corrosion inhibitors. Corros Sci. 2011;53:3873-3898.

9. Patrick GL. An introduction to medicinal chemistry. Oxford: Oxford Univ Press; 2013.

10. Sangeetha M, Rajendran S, Muthumegala T, et al. Green corrosion inhibitors-An overview. Zastita Mater. 2011;52:3-19.

11. Kumar A, Bashir S. Ethambutol: A New and Effective Corrosion Inhibitor of Mildsteel in Acidic Medium. Russ J Appl Chem. 2016;89:1158-1163.

12. Delley B. From molecules to solids with the DMol3 approach. J Chem Phys. 2000;113:7756-7764.

13. Materials Studio. Revision 6.0, Accelrys Inc., San Diego, USA, 2013.

14. Mulliken RS. Electronic population analysis on LCAO-MO molecular wave functions. I. J Chem Phys. 1955;23:1833-1840.

15. Sun H. COMPASS: an $a b$ initio force-field optimized for condensed-phase applications overview with details on alkane and benzene compounds. J Phys Chem B. 1998;102:7338-7364.

16. Zhang Z, Tian NC, Huang XD, et al. Synergistic inhibition of carbon steel corrosion in $0.5 \mathrm{M} \mathrm{HCl}$ solution by indigo carmine and some cationic organic compounds: experimental and theoretical studies. RSC Adv. 2016;6:22250-22268.

17. Dahiya S, Lata S, Kumar P, et al. A descriptive study for corrosion control of low-alloy steel by Aloe vera extract in acidic medium. Corros Rev. 2016;34:241-248. 
18. Singh AK, Quraishi M. Adsorption properties and inhibition of mild steel corrosion in hydrochloric acid solution by ceftobiprole. J Appl Electrochem. 2011;41:7-18.

19. Eddy N, Odoemelam S, Ekwumemgbo P. Inhibition of the corrosion of mild steel in H2SO4 by penicillin G. Sci Res Essays. 2009;4:33-38.

20. El Makrini B, Toumiat K, Lgaz H, et al. Corrosion protection of mild steel in hydrochloric acid solutions in presence of 5-(Benzyloxy)indole - Monte Carlo simulation, weight loss and electrochemical studies. Res J Pharm Biol Chem Sci. 2016; 7:2286-2294.

21. Lgaz H, Salghi R, Jodeh S, et al. Effect of clozapine on inhibition of mild steel corrosion in 1.0 M HCl medium. J Mol Liq. 2017;225:271-280.

22. Singh RN, Kumar A, Tiwari RK, et al. A combined experimental and theoretical (DFT and AIM) studies on synthesis, molecular structure, spectroscopic properties and multiple interactions analysis in a novel ethyl-4[2-(thiocarbamoyl)hydrazinylidene.-3,5-dimethyl-1H-pyrrole-2-carboxylate and its dimer. Spectrochim Acta A. Mol Biomol Spectrosc. $2013 ; 112$ :182190.

23. Jafari H, Danaee I, Eskandari H, et al. Combined computational and experimental study on the adsorption and inhibition effects of $\mathrm{N} 2 \mathrm{O} 2$ schiff base on the corrosion of API 5L grade B steel in $1 \mathrm{~mol} / \mathrm{L} \mathrm{HCl}$. J Mater Sci Technol. $2014 ; 30: 239-252$.

24. Pearson RG. Absolute electronegativity and hardness: application to inorganic chemistry. Inorg Chem. $1988 ; 27$ :734-740.

25. Sastri V. Perumareddi J. Molecular orbital theoretical studies of some organic corrosion inhibitors. Corrosion. 1997 ;53:617-622.

26. Martinez S. Inhibitory mechanism of mimosa tannin using molecular modeling and substitutional adsorption isotherms. Mater. Chem. Phys. $2003 ; 77: 97-102$.

27. Lukovits I, Kalman E, Zucchi F. Corrosion inhibitors-correlation between electronic structure and efficiency. Corrosion. $2001 ; 57: 3-8$.

28. Pearson RG. Absolute electronegativity and hardness: application to inorganic chemistry. Inorg Chem. 1988 ;27:734-740.

29. Cao Z, Tang Y, Cang H, et al. Novel benzimidazole derivatives as corrosion inhibitors of mild steel in the acidic media. Part II: Theoretical studies. Corros Sci. $2014 ; 83$ :292-298.

30. Kokalj A. On the HSAB based estimate of charge transfer between adsorbates and metal surfaces. Chem Phys. $2012 ; 393: 1-12$.

31. Saadouni M, Larouj M, Salghi R, et al. Corrosion control of carbon steel in hydrochloric acid by Sulfaguandine: Weight loss, electrochemical and theoretical studies. Pharm Lett. $2016 ; 8$ :65-76.

32. Wazzan NA. DFT calculations of thiosemicarbazide, arylisothiocynates, and 1-aryl-2,5-dithiohydrazodicarbonamides as corrosion inhibitors of copper in an aqueous chloride solution. J Ind Eng Chem. 2015 ;26:291-308.

33. Kokalj A. Is the analysis of molecular electronic structure of corrosion inhibitors sufficient to predict the trend of their inhibition performance. Electrochim Acta. $2010 ; 56: 745-755$. 
34. Kovačević N, Kokalj A. Analysis of molecular electronic structure of imidazole-and benzimidazole-based inhibitors: a simple recipe for qualitative estimation of chemical hardness. Corros Sci. $2011 ; 53$ :909-921.

35. Lgaz $\mathrm{H}$, Benali $\mathrm{O}$, Salghi $\mathrm{R}$, et al. Pyridinium derivatives as corrosion inhibitors for mild steel in $1 \mathrm{M} \mathrm{HCl}$ : Electrochemical, surface and quantum chemical studies. Pharma Chem. $2016 ; 8: 172-190$.

36. El Adnani Z, Mcharfi M, Sfaira M, et al. DFT theoretical study of 7-R3 methylquinoxalin-2 $(1 \mathrm{H})$-thiones $(\mathrm{RH} ; \mathrm{CH} 3 ; \mathrm{Cl})$ as corrosion inhibitors in hydrochloric acid. Corros Sci. $2013 ; 68: 223-230$.

37. Mi H, Xiao G, Chen X. Theoretical evaluation of corrosion inhibition performance of three antipyrine compounds. Comput Theor. Chem. $2015 ; 1072: 7-14$.

38. Saha SK, Ghosh P, Hens A, et al. Density functional theory and molecular dynamics simulation study on corrosion inhibition performance of mild steel by mercapto-quinoline Schiff base corrosion inhibitor. Phys. E Low-Dimens Syst Nanostructures. $2015 ; 66: 332-341$.

39. Kaya S, Kaya C, Guo L, et al. Quantum chemical and molecular dynamics simulation studies on inhibition performances of some thiazole and thiadiazole derivatives against corrosion of iron. J Mol Liq. 2016 ; 219 :497504.

40. Obot IB, Macdonald DD, Gasem ZM. Density functional theory (DFT) as a powerful tool for designing new organic corrosion inhibitors. Part 1: An overview. Corros Sci. $2015 ; 99: 1-30$.

41. Zhang Z, Tian N, Li X, et al. Synergistic inhibition behavior between indigo carmine and cetyl trimethyl ammonium bromide on carbon steel corroded in a $0.5 \mathrm{M} \mathrm{HCl}$ solution. Appl Surf Sci. $2015 ; 357: 845-855$.

42. Xu B, Ji Y, Zhang X, et al. Experimental and theoretical studies on the corrosion inhibition performance of 4-amino-N, N-di-(2-pyridylmethyl)aniline on mild steel in hydrochloric acid. RSC Adv. 2015;5 :56049-56059. 